\title{
Analysis of the performance of the rotary heat exchanger in the real ventilation systems
}

\author{
Andrzej Grzebielec, Artur Rusowicz, Adam Ruciński \\ Warsaw University of Technology, Institute of Heat Engineering, Nowowiejska 21/25, Warsaw 00-665, Poland
}

\begin{abstract}
Manufacturers of rotary heat recovery units describe them as a very high efficiency heat recovery ventilation systems. In a real system this device is not usually operated under optimal conditions. This is due to the daily and annual changes in temperature and relative humidity. In order to determine the parameters of the rotary heat exchanger mathematical model was constructed and then implemented in a development environment. The paper presents the modeling results of job recovery unit working in real conditions with regard to changes in temperature, air velocity and rotor speed. It turns out that on each of the parameters affects the efficiency of the heat recovery process, which demonstrate that the heat exchanger for the better part of the year will be working with much less efficiency than the nominal.
\end{abstract}

Keywords: rotary heat exchanger; heat transfer; finite difference method; energy recovery.

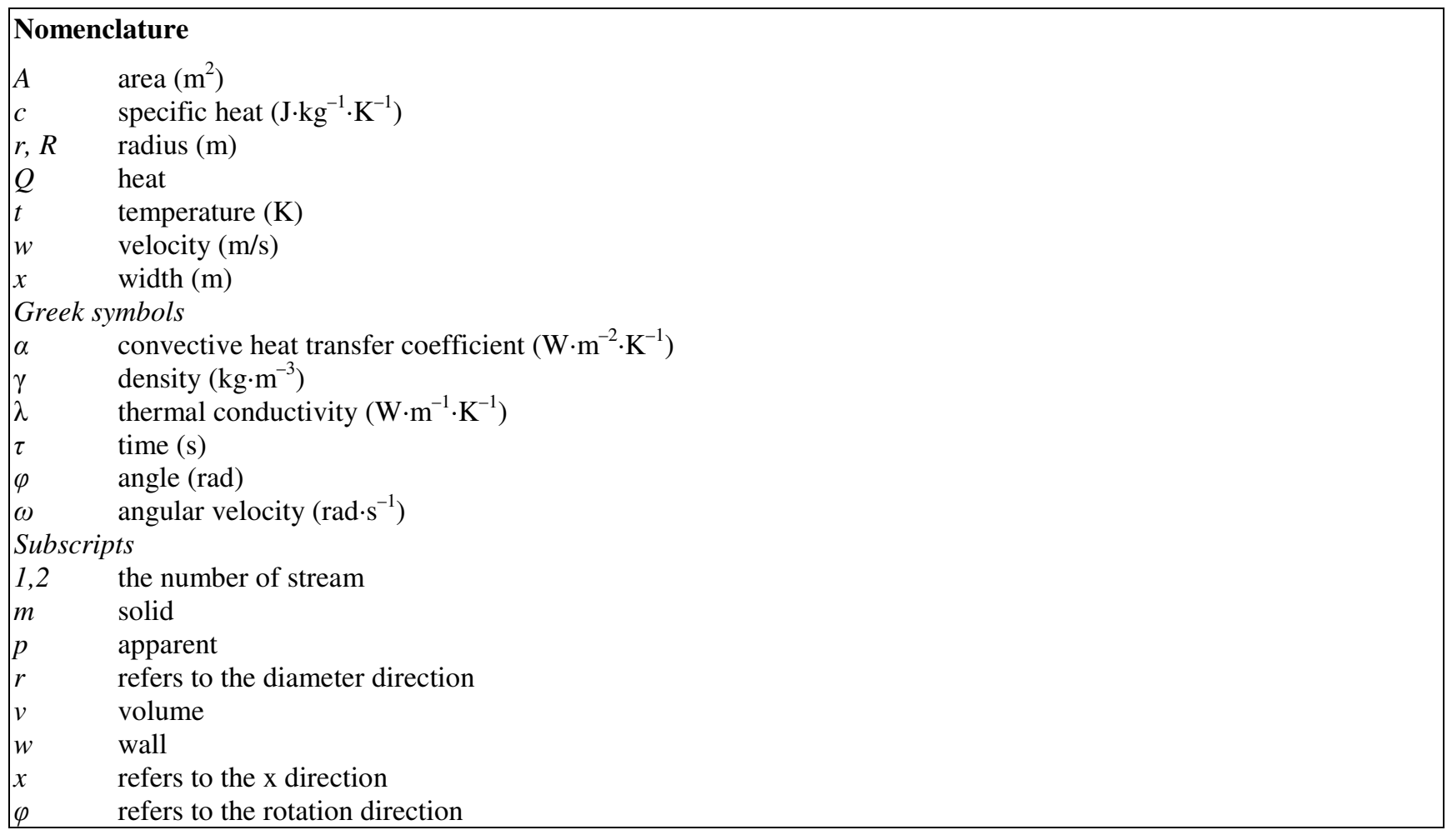

\section{Introduction}

In order to reduce the energy consumption of buildings used more and more solutions are aimed at storage and heat recovery [1-3]. Purposeful also becomes energy obtaining from renewable sources using solar collectors [4], or heat pumps.

Corresponding author: Andrzej Grzebielec. E-mail address: andrzej.grzebielec@itc.pw.edu.pl http://dx.doi.org/10.3846/enviro.2014.259

(C) 2014 The Authors. Published by VGTU Press. This is an open-access article distributed under the terms of the Creative Commons Attribution License, which permits unrestricted use, distribution, and reproduction in any medium, provided the original author and source are credited. 
An analysis of the energy consumption of buildings is apparent that a considerable amount of energy is allocated to the socalled ventilation losses [5]. In existing and operated buildings in Poland, this value ranges from 20 to $40 \%$ of the total energy consumption of buildings. These losses are a result of fresh air for hygienic reasons demand. It is worth noting that in future years the percentage of that portion of the losses will increase in the total balance, because the buildings are built with more and better materials to reduce losses through the walls and windows. In contrast, the quantity of fresh air supplied to the buildings cannot be reduced.

For this reason, a very serious issue becomes a heat recovery process in ventilation and air conditioning systems. From a technical point of view, there are several solutions that enable the reception of heat from the exhaust air stream and transport it to the fresh air stream $[1,6,7]$ :

- rotary heat exchangers;

- counter current heat exchangers;

- heat pumps;

- integrated two-factor intermediate exchangers.

The rest of the work will focus on rotating regenerators, because it is their own people is attributed to the highest heat recovery rates in excess of $90 \%$.

\subsection{Classification of rotary heat exchangers for air conditioning and ventilation processes}

Ventilation and air-conditioning systems meets two configurations of the assets. The first is presented in Figure 1.

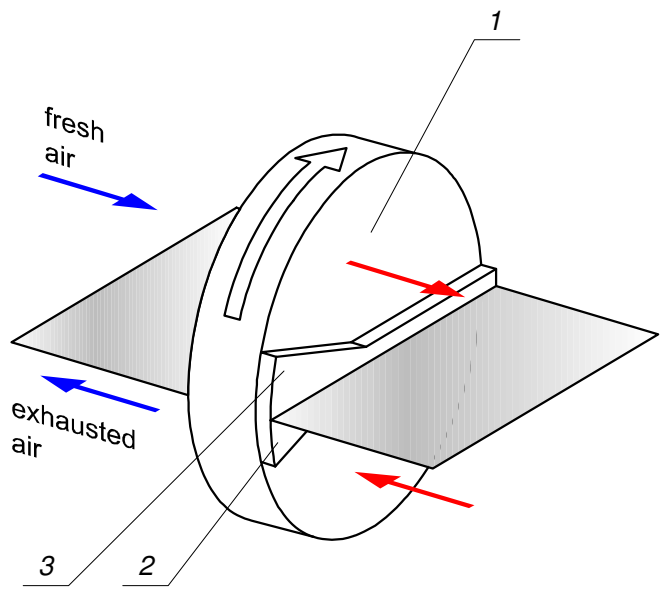

Fig. 1. Typical rotary heat exchanger configuration.

( 1 - rotor, 2 - shutter to prevent the ingress of exhaust air to the supply air duct, 3 - some fresh air cleans the rotor)

Figure 1 is a typical example of the use of the rotary heat exchanger in ventilation. A stream of hot air (exhaust) flows through the heat exchanger releasing heat, and the fresh air stream receives heat from the regenerator. For standard applications, the air streams are the same, and in the case when there is no condensation of the water, the temperature of streams varies by almost the same temperature.

The second use case of rotors which meets in ventilation systems is presented in Figure 2.

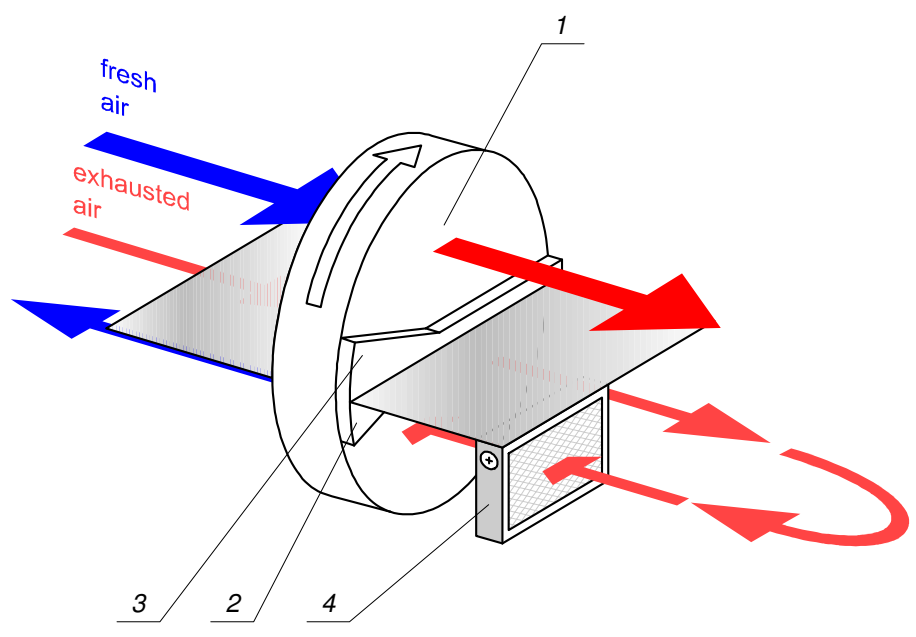

Fig. 2. Rotary heat exchanger used for drying process. 
In this case, the rotary heat exchanger is used to dry the air. The air-conditioning systems over the years used to dry the air coolers. The use of refrigeration equipment for drying is extremely expensive operationally. This is due to the fact that energy must be supplied firstly to cool the air below its dew point, and then needs to be heated, to return to an appropriate temperature. In the case of rotors amount of energy used for drying is much less, since the construction of the rotor the sorbent materials are used.

\subsection{Rotor structure}

Rotors are usually built as shown in Figure 3. These are alternately wound layers of smooth and corrugated metal sheets. Since the rotary heat exchangers are very popular not only in ventilation and air conditioning, but also in the chemical industry there is a great variety of materials from which the rotor is made. For building ventilation systems the most popular material is aluminum, but for a special purpose are also found 1.4571 or 1.4539 steels. Sheet thickness is from 0.07 to $0.2 \mathrm{~mm}$. The amount of corrugated layers is from 1.9 to $2.5 \mathrm{~mm}$.

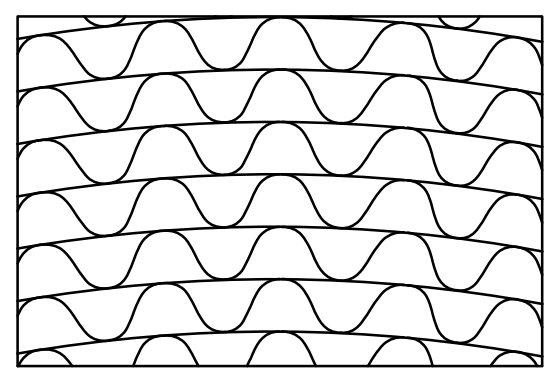

Fig. 3. Rotor cross section

In order to improve the water vapor sorption properties, the metal are coated with the special layers. The most popular are layers made of silica gels and molecular sieves.

\section{Mathematical model}

Although the rotary regenerators are commonly found in industry and air conditioning systems, there is any model well describes the phenomenon of heat transfer [7]. In addition to the heat transfer model should be also recognized a mass transfer model [8]. And the best solution would be if the model additionally takes into account the dynamic operation on the capacity value [9]. Therefore, this article also allows itself to start the construction of such a model. The first step is heat transfer correctly modeled on the basis of the basic equations [10]. The Figure 5 presents a model of the test rotor.

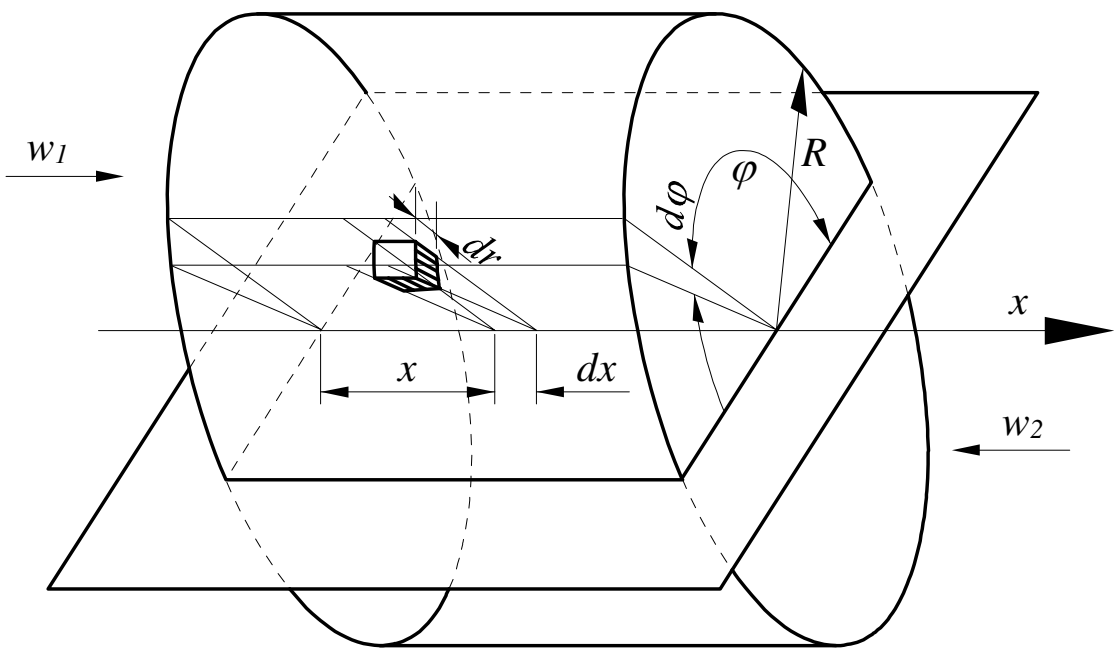

Fig. 4. Graphic model of the rotor

Rotor in the model will be treated as a single body, and the transfer of heat between the sheets of aluminum and the air will be treated as an internal source of heat. This procedure allows to show the heat transfer in the rotor in the Eqn 1).

$$
c_{p} \gamma_{p}\left(\frac{\partial t}{\partial \tau}+w_{x} \frac{\partial t}{\partial x}+w_{r} \frac{\partial t}{\partial r}+\frac{w_{\varphi}}{r} \frac{\partial t}{\partial \varphi}\right)=q_{v}+\lambda_{p, x} \frac{\partial^{2} t}{\partial x^{2}}+\frac{\lambda_{p, r}}{r} \frac{\partial}{\partial r}\left(\frac{\partial t}{\partial r}\right)+\frac{\lambda_{p, \varphi}}{r^{2}} \frac{\partial^{2} t}{\partial \varphi^{2}}
$$


Where all the parameters with the index $\mathrm{p}$ are apparent, depending on the ratio of the volume of material to the total volume. In the case of the coefficient $\lambda$, will be as many as three different values - this is due to the structure of the material in the $x, r$ and $\varphi$ direction. These values are calculated in such a way that conduction through the air will be omitted due to the large difference between the coefficients of thermal conductivity for the aluminum and air.

Since the movement of the test piece will be only in the rotational direction Eqns (2) can be written:

$$
\begin{aligned}
& w_{x}=0 \\
& w_{r}=0 \\
& w_{\varphi}=\omega r
\end{aligned}
$$

In addition to the steady state Eqn (3) is correct

$$
\frac{\partial t}{\partial \tau}=0
$$

and heat transfer between the air and ground repeater will be written as an internal heat source in Eqn (4).

$$
q_{v}=\alpha_{1} A\left(t_{1}-t_{w}\right)
$$

Because the sheets inside the regenerator are thin, and have significantly higher thermal conductivity than air, Eqn (5) can be written:

$$
t_{w}=t_{m}=t
$$

All these assumptions make the Eqn (1) can be simplified to Eqn (6)

$$
c_{p} \gamma_{p} \omega \frac{\partial t}{\partial \varphi}=\lambda_{p, x} \frac{\partial^{2} t}{\partial x^{2}}+\frac{\lambda_{p, r}}{r} \frac{\partial}{\partial r}\left(\frac{\partial t}{\partial r}\right)+\frac{\lambda_{p, \varphi}}{r^{2}} \frac{\partial^{2} t}{\partial \varphi^{2}}+\alpha_{1} A\left(t_{1}-t\right)
$$

\subsection{The solution of equation}

In this embodiment, equations cannot be solved analytically. In order to solve the equation was built a computer program using the method of finite differences. The program was written in C++ language using Microsoft Visual Studio 2010 environment. In the case of the air velocity through the regenerator is from 2 to $6 \mathrm{~m} / \mathrm{s}$ the flow is laminar in nature (hydraulic diameter is equal near to $3 \mathrm{~mm}$ and Reynold's Number for this diameter and velocity $6 \mathrm{~m} / \mathrm{s}$ is about 1500). Which in practice means that the Nusselt number is constant at value about 4.36 for channels with hydraulic diameter equal to $1 \mathrm{~mm}$ [11], and $\mathrm{Nu}=2.3-2.4$ for channels larger than $2 \mathrm{~mm}$ hydraulic diameter [7].

\section{The modeling results}

Using the application created to solve the equation the specified temperature distribution in the regenerator and the heat reception efficiency of the regenerator in a few cases was obtained. There was modeled rotator with $0.86 \mathrm{~m}$ outside diameter and $0.05 \mathrm{~m}$ inside diameter with $0.4 \mathrm{~m}$ length. Rotator was made from aluminum without any absorption layer. Because the hydraulic diameter for modeled rotator was near to $3 \mathrm{~mm}$ the Nusselt Number was used at 2.4 value.

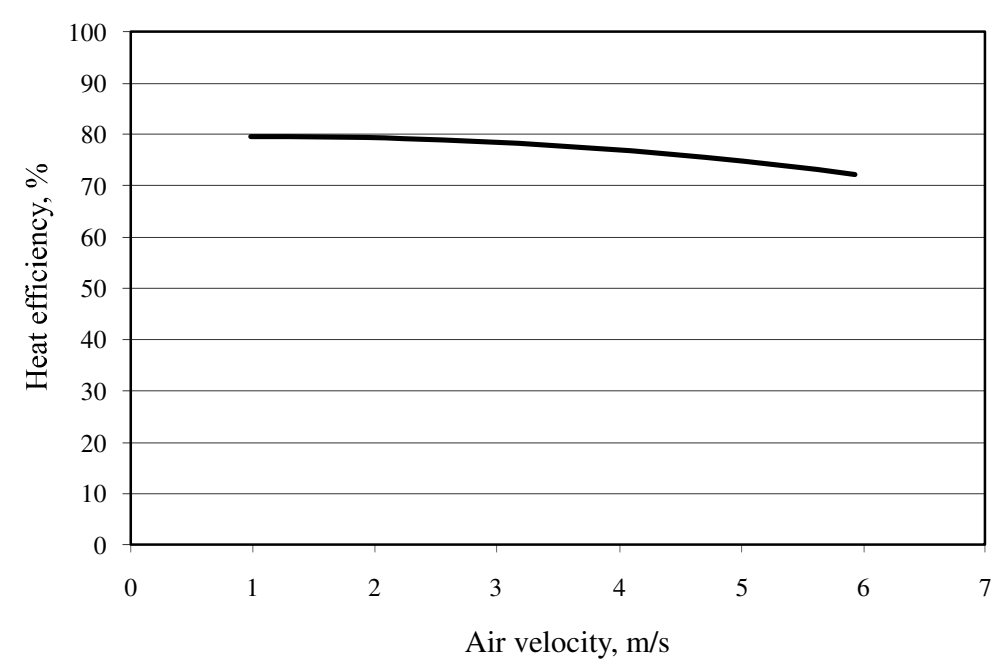

Fig. 5. Influence of the air velocity on the rotary heat exchanger efficiency 
The Figure 5 presents the effect of air velocity on the effectiveness of the regenerator. It can be seen that with the increase in the speed of air flow decreases the effectiveness of the regenerator. The nature of the curve comes from the fact that at higher air velocities, the heat is exchanged only when regenerator transition from one air channel to another. In a further phase of regenerator rotation temperature is close to the temperature of the air which causes the greater part of the rotation do not cause heat exchange between air and regenerator.

In Figure 6 there was presented the dependence of heat recovery efficiency as a function of the temperature difference between the temperature of the fresh air and the temperature of the exhaust air. There is a clear correlation, the smaller the temperature difference in the effectiveness of the regenerator less.

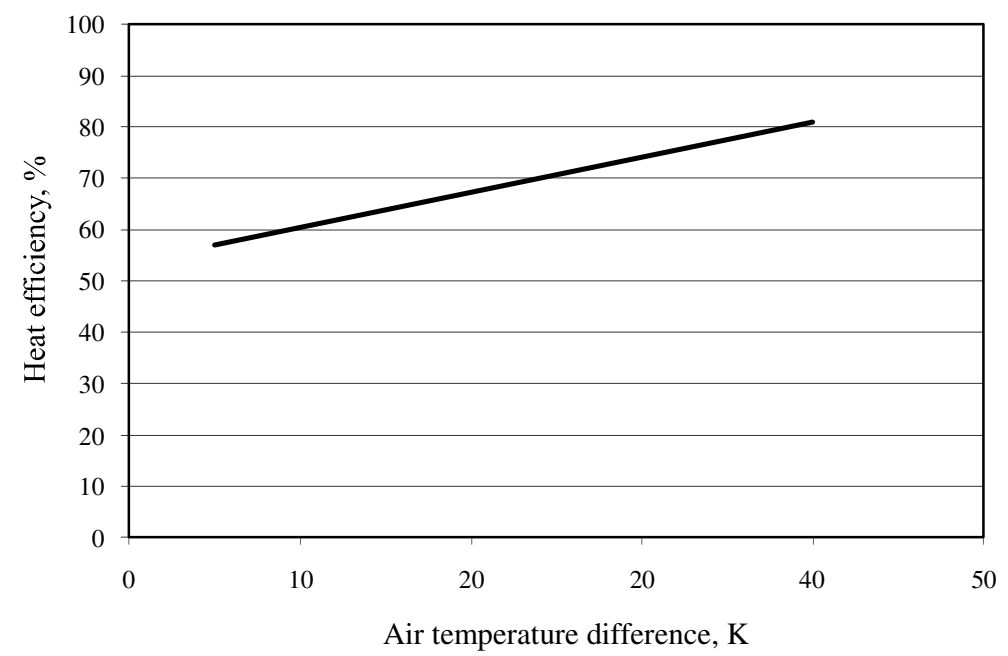

Fig. 6. Influence of the air temperature difference on the rotary heat exchanger efficiency

In the Figure 7 was presented dependence regenerator efficiency as a function of the rotational speed of the rotor of the regenerator for typical speeds encountered in ventilation systems.

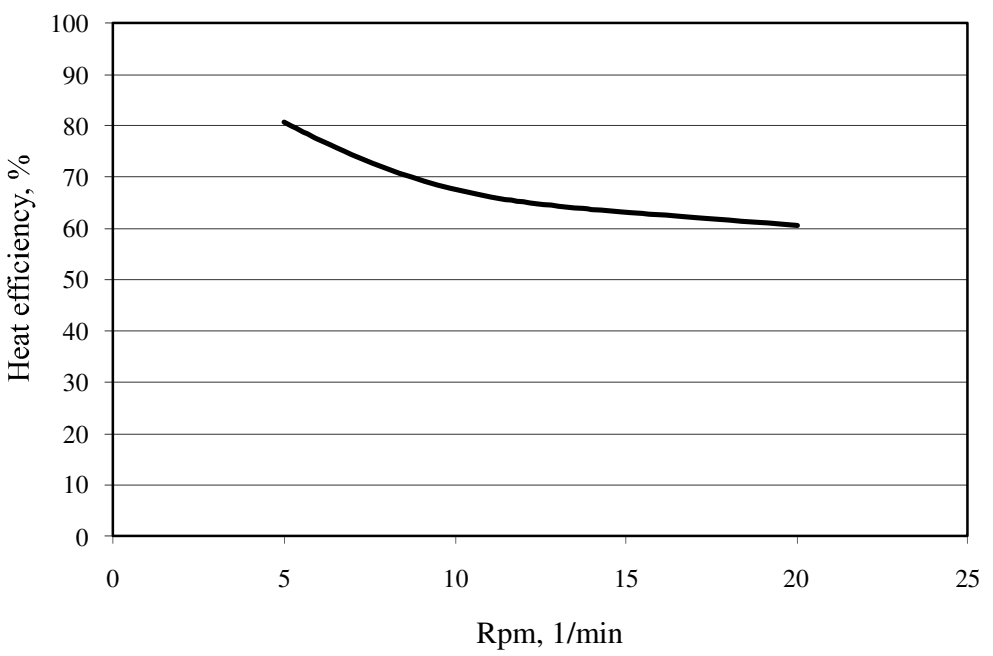

Fig. 7. Influence of the rotor speed on the rotary heat exchanger efficiency

As speed increases, the efficiency decreases. This is due to the fact that the regenerator has not kept pace with the change in temperature.

\section{Conclusions}

Results confirm that the rotary heat recovery units are working with a very large variability in efficiency. The most important issue from a technical point of view is the influence of the air temperature difference. Clearly, the smaller the temperature difference at the inlet between the two streams, the less the possibility of heat recovery. This is due to the fact that part of the heat is exchanged directly through the heat conduction in regenerator construction. And at the moment when the temperature difference is small heat transfer by conduction decreases. For the modeled change in the efficiency of the heat exchanger has changed from 56 to $81 \%$. At the same time it must be remembered that the temperature difference of $40 \mathrm{~K}$ in European conditions is several to tens of hours in a year. For example, Polish standard differential temperature for the heating period is about 15-20 degrees. 
The model presented is currently used only for the calculation of heat transfer, but its universality is able to develop it to also take into consideration in the future, the mass transfer (moisture), using analogies combining heat and mass exchange.

\section{References}

[1] Mardiana-Idayu, A.; Riffat, S. B. 2012. Review on heat recovery technologies for building application, Renewable and Sustainable Energy Reviews 16(2): 1241-1255. http://dx.doi.org/10.1016/j.rser.2011.09.026

[2] Chwieduk, D. 2012. Dynamics of external wall structures with a PCM (phase change materials) in high latitude countries, Energy 59: $301-313$. http://dx.doi.org/10.1016/j.energy.2013.06.066

[3] Jaworski, M. 2012. Thermal performance of heat spreader for electronics cooling with incorporated phase change material, Applied Thermal Engineering 35(1): 212-219.

[4] Torres Ledesma, J.; Lapka, P.; Domański, R.; Casares, F. S. 2013. Numerical simulation of the solar thermal energy storage system for domestic hot water supply located in south Spain, Thermal Science 17(2): 431-442. http://dx.doi.org/10.2298/TSCI111216050L

[5] Juodis, E. 2006. Extracted ventilation air heat recovery efficiency as a function of a building's thermal properties, Energy \& Buildings 38(6): 568-573. http://dx.doi.org/10.1016/j.enbuild.2005.07.002

[6] Rusowicz, A.; Grzebielec, A. 2012. The heat exchangers effectiveness in ventilation and air conditioning. Aparatura Badawcza i Dydaktyczna 17(2): 47-52.

[7] Dinglreiter, U. 2011. Heat and mass transfer at rotary heat exchangers in consideration of the condensation potential, Heat and Mass Transfer 47(8): 991-999. http://dx.doi.org/10.1007/s00231-011-0859-8

[8] Grzebielec, A.; Rusowicz, A. 2011. Experimental and theoretical studies on heat and mass transfer in anti-condensation coatings, Archives of Thermodynamics 32(3): 45-56. http://dx.doi.org/10.2478/v10173-011-0012-6

[9] Tofighi, A. 2013. Performance Evaluation of PV Module by Dynamic Thermal Model, Journal of Power Technologies 93(2): 111-121.

[10] Madejski, J. 1998. Heat transfer theory. Szczecin: Publisher Institutional Technical University of Szczecin.

[11] Chien-Yuh, Y.; Chia-Wei, C.; Ting-Yu, L.; Satish G. K. 2012. Heat transfer and friction characteristics of air flow in microtubes, Experimental Thermal and Fluid Science 37: 12-18. http://dx.doi.org/10.1016/j.expthermflusci.2011.09.003 